\title{
Denis de Rougemont oder die Sprengkraft der Liebe in ihrer geschichtlichen Entwicklung im Abendland
}

Machen wir uns nichts vor: Wir haben uns bislang ausschließlich auf das Leben, die Liebe und das Lesen im Abendland konzentriert! Selbstverständlich ist der kulturelle wie auch inter- und transkulturelle Horizont der Literaturen der Welt wesentlich weiter gezogen - und ich werde mich in der Vorlesung immer wieder bemühen, auch ein wenig über unseren abendländischen Tellerrand hinauszuschauen. Denn damit wir begreifen können, was etwa die Liebe im Abendland ausmacht, müssen wir verstehen, wie diese so spezifische Konzeption der Liebe, die sich massenmedial über unseren ganzen Planeten verbreitet, im Konzert und im Beziehungsgeflecht mit anderen Liebeskonzeptionen verwoben ist, und wie sich diese Liebesauffassungen wechselseitig beeinflusst haben. Eben dies ist die tiefgehende Einsicht des frankophonen Schweizer Essayisten Denis de Rougemont.

Ich möchte mich daher nun einem großen, Aufsehen erregenden Buch zuwenden - sozusagen zum Abschluss dieses Eingangsportals zu unserer Vorlesung -, in welchem wir die Entwicklungen der abendländischen Liebeskonzeption(en) aus historischer und zugleich inter- und transkultureller Perspektive näher betrachten werden. Es geht um Denis de Rougemonts L'amour et l'Occident, dessen erste Fassung bereits im Jahre 1939 erschien und das nach dem Zweiten Weltkrieg sehr rasch zu einem vieldiskutierten Standardwerk der Liebesdiskussionen geworden ist.

Es ist nicht ganz zufällig, dass wir mit Denis de Rougemont (1906-1985), diesem Vordenker und Vorkämpfer einer föderalen Europäischen Union und diesem philosophischen Aktivisten des europäischen Gedankens zum Zeitpunkt des Ausbruchs des Zweiten Weltkrieges, einen Literaten und Philosophen vor uns haben, der die grundlegenden Werte Europas oder des Abendlandes zu fassen versucht. Denn die Liebe, ihre Begriffe und Konzeptionen stellen einen derartigen Grundwert für Europa dar - das ist vielleicht die erste Lektion, die wir von diesem engagierten Schweizer lernen dürfen. Wenn heute in einem umfangreichen Vorhaben „A Soul for Europe“, nach einer Seele für Europa gesucht wird, dann dürfte eigentlich Die Liebe und das Abendland von Denis de Rougemont hierbei nicht fehlen. Bis zu seinem Lebensende trat der Schweizer gegen den Nationalstaat und für ein Europa der Regionen in die literarisch-politische Arena und bestach mit einer Vielzahl von Büchern, in denen er die Konsequenzen aus der Katastrophe von Nationalsozialismus und Faschismus ziehen wollte. Im Jahre 1939 aber war in den Zeiten von Hass und Mord ein Buch über die Liebe wahrlich ein gegenzyklisches Unterfangen. 


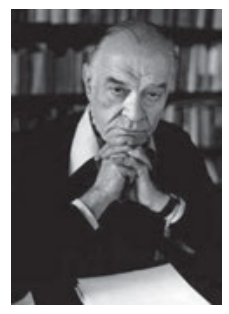

Abb. 41: Denis de Rougemont (Couvet im Kanton Neuenburg, 1906 - Genf, 1985), in den siebziger Jahren.

Nachdem wir eine gleichsam strukturalistisch-poststrukturalistische Sicht des liebenden Subjekts bei Roland Barthes gesehen und näher untersucht haben, nachdem wir mit Italo Calvino zwei Varianten einer literarischen Verbindung zwischen Lesen und Lieben kennengelernt haben, bildet Denis de Rougemonts Buch den Versuch, die Liebe mit der Definition des Abendlandes, und damit als eine geschichtlich gewachsene und gerade mit dem Orient in vielfältigen Austauschbeziehungen stehende Kategorie zu entwickeln - so dass das Abendland, der Okzident, ganz nebenbei aus der Fiktion erlöst wird, ein dem Orient als Gegensatz gegenüberstehendes Totum zu sein, das so gar nichts auf Ebene der hohen Kultur wie der Alltagskultur mit dem Orient zu tun habe. Wir wissen: Das Gegenteil ist der Fall. Diese Fiktion aber wirkt heute noch fort, auch wenn sich intelligente Bücher wie etwa Hans Beltings Florenz und Bagdad dagegen stemmen. ${ }^{1}$ Doch schon Denis de Rougemonts Text zeigte die vielfältigen Verbindungen und Wechselbeziehungen zwischen Orient und Okzident auf. Dies sollten wir uns etwas genauer ansehen!

Denis de Rougemont hat sein Hauptwerk L'amour et l'Occident mehrfach, darunter 1956 und 1971, überarbeitet. Der Schriftsteller, der verschiedenen Institutionen für Europa vorstand und bis zu seinem Lebensende an der Universität Genf tätig war, sieht dabei die Leidenschaft als la tentation orientale de l'Occident und verfolgt sie bis ins 12. Jahrhundert zurück. Es handelt sich folglich um eine historische Tiefenanalyse des westöstlichen Austausches von Liebeskonzepten, die wir heute nur mehr dem Abendland zuzuschreiben gewillt sind. Doch die historische Entwicklung war deutlich komplexer.

In seinem auf Juni 1938 datierten Vorwort zur ersten Ausgabe von L'amour et l'Occident betonte Denis de Rougemont gleich mehrfach den Bezug seines Buches zum Leben, auch und gerade zu seinem eigenen Leben. Ich möchte Ihnen diese Passage, die aus meiner Sicht sehr schön die spezifisch lebenswissenschaftliche Dimension seines Ansatzes verdeutlicht, nicht vorenthalten.

1 Vgl. Belting, Hans: Florenz und Bagdad. eine westöstliche Geschichte des Bildes. München: Beck 2008. 


\section{D. de Rougemont L'amour et l'occident}
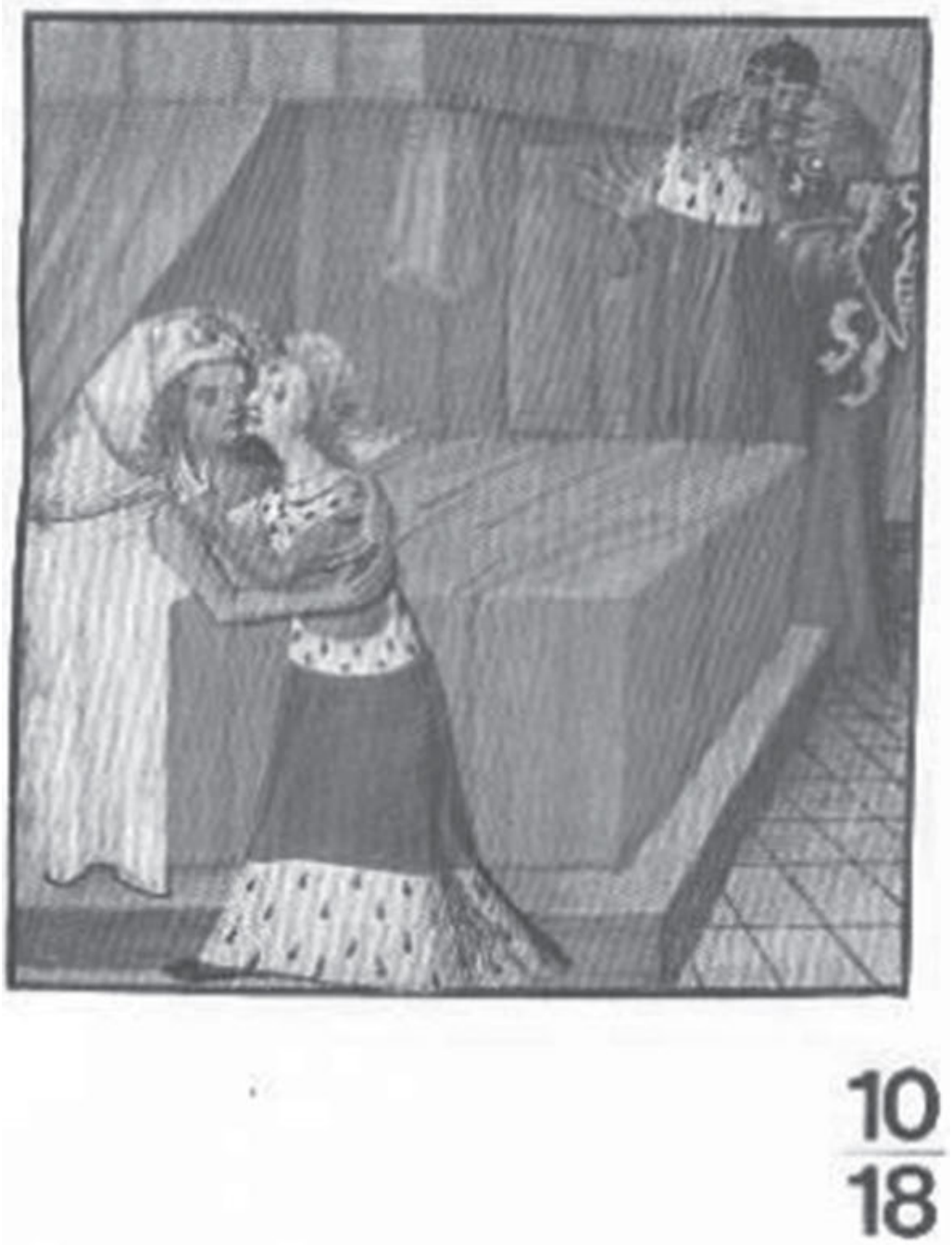

Abb. 42: Cover von Denis de Rougemonts L'amour et l'Occident. 


\begin{abstract}
Dass man es als angenehm empfindet, über alles, was mit Liebe zusammenhängt, zu sprechen, ist ein recht wenig überzeugender Vorwand, wenn es sich um einen so dicken Band handelt. Übrigens ein zweifelhafter Vorzug: man müsste erörtern, ihn mit so und so vielen Bestseller-Autoren zu teilen. Daher habe ich auch einige Schwierigkeiten bewusst in Angriff genommen. Ich wollte das, was Stendhal „leidenschaftliche Liebe“ (l'amour-passion) nennt, weder verschönern noch herabwürdigen, sondern versuchen, es als ein historisches Phänomen eigentlich religiösen Ursprungs zu beschreiben. Nun dulden Männer und Frauen es sehr wohl, dass man von Liebe spricht, ja, sie werden dessen nie überdrüssig, so alltäglich die Rede auch sein mag; sobald man aber anfängt, die Leidenschaft zu definieren, und sei es auch mit noch so wenig Strenge, werden sie kopfscheu. [...] Daraus folgt, dass dies Buch seine Notwendigkeit in dem Maße zeigen wird, wie es Missfallen erregt; seine Nützlichkeit wird es überhaupt nur unter Beweis stellen können, wenn es die überzeugt, die sich bei seiner Lektüre der Gründe bewusst werden, die sie für ihr anfängliches Misstrauen anführen könnten. [...]

Wozu Zeit und Worte verlieren, um immer wieder zu erklären, dass die Wirklichkeit sehr viel komplexer ist als alles, was man darüber zu sagen vermag. Wenn das Leben unübersichtlich ist, so bedeutet das nicht, dass ein Buch es hierin nachahmen soll. ${ }^{2}$
\end{abstract}

An diesem Zitat wird deutlich, dass de Rougemont bei seinen Leserinnen und Lesern - und er sprach ganz explizit in seinem ersten Vorwort zum einen von den männlichen Gelehrten, zum anderen von den weiblichen Leserinnen - nicht nur ein hohes Interesse, sondern auch große Widerstände dagegen vermutete, über Liebe anders $\mathrm{zu}$ sprechen als im vertraulichen, fast intimen, in jedem Falle unsystematischen Ton der Konversation. Liebe ist also ein tolles Thema, so Rougemont, doch der Glaube sei weit verbreitet, die Liebe eigne sich nicht für wissenschaftliche Untersuchungen und Definitionen. Nun, wir haben ja schon mit Roland Barthes eine sehr prägnante und kreative Antwort auf diese grundlegende Herausforderung für jeglichen systematischen Diskurs über Liebe gefunden.

Mit seinen Vorbehalten lag Denis de Rougemont durchaus richtig. Denn das Buch hat Rougemont sehr viel Kritik von allen Seiten eingetragen; und gleichwohl ist es zu einem Klassiker geworden - vielleicht auch, weil es im Grunde nur wenige solcher Bücher über die Liebe gibt. Vergessen wir nicht, dass Roland Barthes mit guten Gründen nicht zuletzt auch über die absolute Einsamkeit eines Diskurses über die Liebe sprach. Es gibt also eine seltsame Koinzidenz zwischen einem großen öffentlichen Interesse und einem hohen, vom Autor zu überwindenden Widerstand gegen eine wissenschaftliche Behandlung dieses Themas der Liebe.

2 De Rougemont, Denis: L'amour et l'Occident. Édition définitive. Paris: Plon 1972, hier S. $7 \mathrm{f}$. 
Nun folgt ein kleines Geständnis, nach mehr als hundert Seiten: Ich habe diese Passage aus dem Vorwort nicht zuletzt aus dem Grund gewählt, um Ihnen eben jene Befürchtung oder Skepsis anzuzeigen, die auch mich selbst beschlich und beschleicht, wenn ich Ihnen in dieser Vorlesung von der Liebe berichten und die Liebe analysieren will. Im Grunde hat sich an diesem Wagnis nicht viel geändert, sehen wir einmal von der Tatsache ab, dass es mittlerweile klar ist, dass nicht nur Roland Barthes, sondern auch Denis de Rougemont zu BestsellerAutoren geworden sind, die nicht nur ihr Thema, sondern auch ihre Bücher gut verkauft haben. Letzteres wiederum ist keine Motivation für unsere Vorlesung, umschreibt aber die große Öffentlichkeit, welche dem Thema Liebe im Allgemeinen sicher ist. Und es ist ein Themenkreis, der ohne die zentrale Berücksichtigung der Literaturen der Welt nicht anzugehen ist.

Entscheidend im obigen Zitat ist freilich, dass Rougemont den Bezug zum Leben herstellt. Dabei betont er, dass ein Buch nicht von derselben Komplexität sein solle wie das Leben: Es ist - um mit Jurij Lotman zu sprechen - ein sekundäres modellbildendes System, ${ }^{3}$ das die Liebe eben gerade in ihrer Systemhaftigkeit darzustellen vermag, weil es das primäre System in seiner Komplexität nicht simpel nachahmt oder - wie man auch sagen könnte - widerspiegelt, sondern eine wie auch immer geartete Abstraktionsebene einführt. Es ist eben ein Modell (und eine Modellierung) der außersprachlichen Wirklichkeit und nicht diese selbst.

Letztlich aber bleibt der Bezug zum Leben aufrechterhalten. Es gibt sozusagen keine vollständige Emanzipation des Buches vom Leben, im Gegenteil: Der Anspruch, etwas Neues herauszubekommen und zugleich damit auf das Leben zurückzuwirken, wird mitnichten aufgegeben. So meinte Rougemont auch im Vorwort zu seiner Auflage von 1956, er habe nichts von der zahlreichen Kritik vergessen, der man sein Buch unterzogen habe, im Gegenteil: Er habe manches hinzugelernt. Doch fährt er im unmittelbaren Anschluss fort: „übrigens mehr durch das Leben als durch die Lektüre meiner Kritiker, denn die waren sich kaum einig“. ${ }^{4}$ So wurde selbst die Arbeit am fertigen Buch und dessen kritischer Überarbeitung im Zeichen des Lebens vorgenommen, was letztlich bedeutet, dass für Rougemont das Leben und der Bezug zu ihm zum Gradmesser der Beurteilung eines Buches avancieren. Dies in dieser Direktheit auszudrücken ist bemerkenswert.

3 Vgl. Lotman, Jurij M.: Die Struktur literarischer Texte. Übersetzt von Ralf-Dietrich Keil. München: W. Fink ${ }^{2} 1981$.

4 De Rougemont, Denis: L'amour et l'Occident, S. 11. 
Doch es handelt sich zweifellos zugleich um einen gefährlichen Standpunkt. Das Leben - und insbesondere das individuelle und subjektiv wahrgenommene Leben - kann nicht als überzeugender Gradmesser und als objektive Beurteilungsinstanz eines wissenschaftlichen Werkes gelten, auch wenn ein Essayist wie Rougemont hier wesentlich größere Spielräume hat als ein Literaturwissenschaftler. Aber wir könnten aus diesen Ausführungen doch lernen, wie wichtig es ist, den Bezug zur Lebenswirklichkeit und zum Lebensvollzug aufrechtzuerhalten, soll der Wissenschaft auch künftig ein (hoffentlich wieder größer werdender) Sitz im Leben zugeschrieben werden können. Behalten wir folglich diesen lebenswissenschaftlichen Aspekt von L'amour et l'Occident im Auge!

Lassen Sie uns an dieser Stelle auf den Auftakt von Rougemonts Die Liebe und das Abendland eingehen, bevor wir uns mit der zentralen historischen These des Buches auseinandersetzen. Denn Rougemont ist ein Meister seines Faches; und so hat er selbstverständlich bereits zu Beginn die Köder ausgelegt, welche die Leserschaft anlocken und für den Rest der Lektüre interessieren sollen. Mithin heißt es im ersten, dem Tristan-Mythos gewidmeten Kapitel:

Liebe und Tod, Liebe, die zum Tode führt: ist das nicht die ganze Dichtung, so doch wenigstens all das, was volkstümlich ist, all das, was in unseren Literaturen allgemein bewegend ist, in unseren ältesten Legenden und in unseren schönsten Liedern. Die glückliche Liebe hat keine Geschichte. Es gibt Romane nur von der Liebe, die zum Tode führt, d.h., von der bedrohten und vom Leben selbst verdammten Liebe. Was die abendländische Liebe begeistert, ist nicht die Sinnenfreude oder der reiche Frieden der Vermählten. Es ist weniger die erfüllte Liebe als die Leidenschaft der Liebe. Und Leidenschaft bedeutet Leiden. Darin liegt der innere Sinn.

Aber die Begeisterung, die wir für den Roman und den Film, der aus diesem Roman entstanden ist, zeigen, die idealisierte Erotik, die sich durch unsere ganze Kultur, unsere Erziehung, die Bilder, die unser Leben verschönen, hindurchzieht, endlich das verzweifelt gewordene Bedürfnis nach einer Ausflucht, hervorgerufen durch den Überdruß an unserer technisierten Welt, alles in und um uns verherrlicht die Leidenschaft in einem solchen Maße, daß wir dahin gekommen sind, in ihr die Verheißung eines lebendigen Lebens zu sehen, eine Macht, die verklärt, etwas, was jenseits von Glück und Leiden liegt, eine glühende Glückseligkeit. ${ }^{5}$

Auch in dieser Passage fällt die Frequenz des Lexems „Leben“ auf. Immer wieder wird in diesem Zitat die Dimension der Liebe auf eine Gruppe von Menschen, die des Abendlands, bezogen, die sich durch eine Liebeskonzeption definieren, welche an der Leiden schaffenden Leidenschaft ausgerichtet ist. Ist unsere, die abendländische Kultur also eine leidende, gar eine agonale Kultur? Die narrative Dimension von Liebe, so scheint es, beschränkt sich allein auf diese Dimension:

5 De Rougemont, Denis: L'amour et l'Occident, S. $15 \mathrm{f}$. 
Alles andere sei nicht zu erzählen, habe keinerlei Geschichte. Dem widerspricht natürlich durchaus das happy-ending vieler Hollywood-Filme oder Arztromane aber das wusste Denis de Rougemont auch selber.

Doch selbst in diesen Geschichten, in diesen Narrationen gibt es stets die Dimension des Leidens, denn sonst gäbe es keine Geschichte, auch nicht eine solche, die auf ein geteiltes Glück hinausläuft. Rougemont aber ging es darum aufzuzeigen, wie sehr unsere Kultur von der Leidenschaft und mehr noch von der Verheißung der Leidenschaft durchtränkt ist, wie sehr wir also mit der Liebeskonzeption letztlich auch eine Lebenskonzeption teilen, in der die Leidenschaft und auch und gerade das Leiden erst auf Erfüllung warten - ob in diesem oder einem anderen Leben. Die Parallelen zu religiösen Vorstellungen und spirituellen Handlungsweisen sind bei dieser Darstellungsweise offensichtlich.

Aufschlussreich ist auch, wie stark Rougemont - geradezu heideggerianisch - in seinem Buch auf der Dimension der Liebe zum Tode sowie des Daseins zum Tode insistiert. Eros ist damit schon immer mit Thanatos verknüpft, so wie im Liebesakt - dem Lebensakt par excellence - auch immer schon der Tod, zumindest der kleine Tod, gegenwärtig ist. Liebe und Tod sind, wie wir noch sehen werden, ein kaum voneinander zu trennendes Geschwisterpaar. Eine Liebeskultur dieser Art impliziert damit immer den Tod und ist auf diese Weise stets auch eine Todeskultur. Freilich kann man sich sehr wohl darüber streiten, ob alle Dichtung wirklich Liebesdichtung ist, die zum Tode führt. Dagegen ließen sich durchaus gewichtige Argumente ins Feld führen. Doch auf den kleinen Tod im Liebesakt, im Spiel von Körper-Haben und Leib-Sein, kommen wir noch zurück.

Die Leidenschaft als zentrale Dimension der Liebe ist - ganz im Stendhal'schen Sinne - letztlich immer auch mit einem Erkenntniswillen gepaart, ganz so, wie wir dies in Italo Calvinos Il barone rampante bei Viola und Cosimo gesehen hatten, die sich selbst und den jeweils anderen im Liebesakt neu wahrnahmen und erkannten. Liebe, so ließe sich sagen, ist im vollen Wortsinne immer auch Sehnsucht nach einer Erkenntnis, nach einer Erkenntnis des anderen, ja mehr noch: das Begehren einer Erkenntnis, die sich im anderen, im geliebten Objekt, verkörpert und Gestalt annimmt. Der Wille zur Liebe ist insoweit nicht nur Wille zur Macht und vielleicht auch Wille zum Tod - das werden wir später noch vielfach finden -, sondern auch Wille zur Erkenntnis, welche sich im Anderen verkörpert und im Ich vollzieht. Dies scheint mir eine wichtige und anhand möglichst vieler literarischer Texte zu überprüfende Dimension von Liebe insgesamt zu sein.

Denis de Rougemont hat seine Thesen immer wieder vorgetragen und leicht variiert; und so werden Sie manches auch in der folgenden Passage wiederfinden, was wir bereits besprochen haben. Jedoch scheint es mir wichtig, diesem Insistieren und der Variation eines bestimmten Gedankens hier etwas Raum zu geben und Rougemont erneut zu Wort kommen zu lassen: 
Mir scheint, das erklärt ein gut Teil unserer Psyche. Ohne Hindernisse bei der Liebe gäbe es keinen „Roman“. Aber den Roman liebt man ja gerade, d.h. das Bewusstsein, die Intensität, die Variationen und das Aufschieben der Leidenschaft, ihr Crescendo bis zur Katastrophe und nicht etwa ihr allzu schnelles Sichverzehren. Sehen Sie sich unsere Literatur an. Das Glück der Liebenden bewegt uns nur durch die Erwartung des Unglücks, das es bedroht. Diese Bedrohung des Lebens und die feindselige Wirklichkeit, die es in irgendein Jenseits verlegen, sind geradezu notwendig. Die Sehnsucht, das Erinnern bewegen uns, und nicht die Gegenwart. Die Gegenwart ist unausdrückbar, sie besitzt keine fühlbare Dauer, sie kann nur ein gnadenreicher Augenblick sein - das Duett von Don Juan und Zerlina. Oder man verfällt in ein Postkartenidyll.

Die glückliche Liebe hat in der abendländischen Literatur keine Geschichte. Und die Liebe, die nicht gegenseitig ist, gilt nicht als wahre Liebe. Das ist der große Fund der Dichter Europas, das, was sie vor allem in der Weltliteratur auszeichnet, was am tiefsten die Besessenheit des Europäers zum Ausdruck bringt: Erkenntnis durch den Schmerz hindurch, das ist das Geheimnis des Tristanmythos, die leidenschaftliche Liebe, die zugleich geteilt und bekämpft wird, die um ein Glück bangt, das sie zurückstößt, die in ihrer Katastrophe verherrlicht wird; die gegenseitige unglückliche Liebe. [...]

Gegenseitige Liebe in dem Sinne, dass Tristan und Isolde sich gegenseitig lieben, oder wenigstens davon überzeugt sind. Sie sind ja wirklich einer dem anderen in einer beispielhaften Weise treu. Das Unglück aber ist, dass die Liebe, die sie „lenkt“, nicht die Liebe zum anderen ist, wie dieser in seiner konkreten Wirklichkeit ist. Sie lieben einander, aber jeder liebt den anderen nur von sich selbst, nicht vom anderen her. ${ }^{6}$

In dieser Passage wird die These von der glücklichen Liebe, die keine Geschichte hat und daher auch kein Roman sein kann, wieder aufgenommen und mit einigen Hinweisen auch narrativer Art - etwa auf die Notwendigkeit, kein schnelles Sich Verzehren zu erlauben - erweitert. Dies ist fast schon ein Schreibrezept für Liebesromane - zumindest auf hohem Niveau und eher ohne den Anspruch, jemals zum Bestseller zu werden. Glück - und zumal Liebesglück - interessiert nur in seiner Bedrohung, in seinem Bedroht-Sein durch Unglück: so zumindest in der abendländischen Kultur. Nur dann wird eine literarische Geschichte daraus.

Bemerkenswert und aufschlussreich ist auch der Hinweis auf die Gegenwart, die uns nicht interessiere. Denn diese Gegenwart ist immer noch Vergangenheit oder vielleicht auch schon Zukunft, auf die sie immer verweist. Natürlich ist hier auch an die Untersuchung zu denken, dass wir Gegenwart empirisch gesehen als einen Zustand von sehr kurzer Dauer, von nur wenigen Sekunden wahrnehmen. Denn schon nach wenigen Sekunden ist laut experimentellen Untersuchungen eine Wahrnehmung der Vergangenheit überantwortet, und die Bewegung, die ich gleich ausführen werde, der Satz, den ich gleich sprechen werde, sind immer schon der Zukunft zugehörig. So ist es folglich auch mit der Liebe, die immer entweder noch Erinnern oder schon Sehnsucht ist. So passt

6 De Rougemont, Denis: L'amour et l’Occident, S. $54 \mathrm{f}$. 
das geflügelte Zitat aus Goethes Faust I (um V. 1700) hier auch in seiner agonalen Dimension sehr gut: „Werd ich zum Augenblicke sagen: / Verweile doch! du bist so schön! / Dann magst du mich in Fesseln schlagen, / Dann will ich gern zugrunde gehn!“

Was die Literaturen Europas innerhalb der Weltliteratur auszeichne, so Denis de Rougemont, sei die Erkenntnis durch den Schmerz hindurch. Dies meint im Grunde eine Bemerkung, die ich vor wenigen Zeilen gemacht habe: dass Liebe nämlich stets ein Versuch der Gewinnung von Erkenntnis ist. In der Liebe stoßen wir oft auf eine Sehnsucht nach Erkenntnis - und genau hierin sind sich Tristan und Isolde auch durch ihre Liebe treu. Der Tristanmythos aber zeigt, folgen wir der Analyse von Denis de Rougemont, dass es hier nicht um die Erkenntnis des Anderen geht, sondern um die Erkenntnis des Ich.

Diese Selbsterkenntnis ist gewiss ein hehres Ziel; und letztlich ist jede Erkenntnis in gewissem Maße immer auch Selbsterkenntnis. Sobald sie aber sich dogmatisch durchsetzt und die Erkenntnis des anderen zurückdrängt, ist die Liebe als wechselseitige Wahr-Nehmung fraglos gefährdet. In diesem Sinne könnte man auf der körperlichen Ebene auch von der wechselseitigen Benutzung primärer Geschlechtsmerkmale sprechen, so wie dies Immanuel Kant in einem bekannten Zitat formulierte. Sollen wir das als Liebe bezeichnen?

Innerhalb einer abendländischen Tradition, so jedenfalls Denis de Rougemont, können wir dies nicht. Damit fällt schon mal eine Unmenge an Pornographie in unserer Gegenwart, aber auch bereits in der Vergangenheit weg. Liebe wäre in diesem Sinne also die Liebe zum Anderen, wie dieser in einem ganz konkreten Sinne ist: So, wie er ist, so, wie sie ist, so, wie sie sind. Zugleich haben wir es mit der Selbstliebe, dem Narzissmus zu tun, den es in jeder Liebesbeziehung gibt und geben muss, der aber in einer absolut dominanten Art die Liebe im abendländischen Sinne verunmöglicht und zum Scheitern führt.

Denis de Rougemont hat sich den Mythos von Tristan und Isolde nicht als einen schieren literarischen Text, sondern als einen Mythos ausgesucht. Und dies heißt für ihn: als eine (künstlerische) Form, die Macht über die Menschen hat. Zugleich steht der Tristan-Mythos laut Rougemont für die Beziehungen zwischen Mann und Frau in einer bestimmten sozialen Gruppe, jener nämlich der abendländischen Ritterschaft im zwölften und dreizehnten Jahrhundert. Insoweit ist für den Schweizer Essayisten der Rückgriff auf den Mythos immer auch - so könnten wir mit Hans Blumenberg formulieren - eine Arbeit am Mythos ${ }^{7}$ und zugleich ein Griff zu einer historischen Form der Liebe: zu einem bestimmten Zeitpunkt und in einer bestimmten Gesellschaft sowie gesellschaftlichen Gruppe; damit der Zugriff

7 Vgl. Blumenberg, Hans: Arbeit am Mythos. Frankfurt a. M.: Suhrkamp 1979. 
auf eine bestimmte Entwicklungsgeschichte von Liebe, welche freilich - so der Autor - folgenreich gerade auch für uns selbst geworden ist.

Mit großer Häufigkeit findet sich bei Rougemont das Insistieren auf dem Überspringen des Mythos und der Literatur ins Leben, eine Beziehung, die wir lebenswissenschaftlich deuten dürfen. Der Tristan-Mythos wird gleichzeitig auch als die Gestaltung des Ehebruchmotivs verstanden, ein Verständnis, das in vielen anderen Geschichten dann immer wieder auf direkte oder indirekte Weise zum Vorschein kommt. Für den Autor von L'amour et l'Occident bietet der TristanMythos die Möglichkeit, die Differenz zwischen einer Konzeption der Liebe als Leidenschaft und der Konzeption als Ehe aus christlicher Sicht immer wieder aus anderen Perspektiven auszuhandeln und diesen Mythos gleichsam als Zentralachse jeglicher Geschichte der Entwicklung des Mythos herauszuarbeiten. Diese Möglichkeit erklärt, warum Tristan in diesem Buch eine solche Dominanz besitzt.

An dieser Stelle erscheint es sinnvoll, Ihnen einmal in verkürzter Form den Mythos von Tristan und Isolde - in Anlehnung an Rougemont - ins Gedächtnis zu rufen, wobei hier im Grunde die fünf verschiedenen Fassungen des Mythos, die ihrerseits auf einer unbekannten Urfassung beruhen und wiederum zum Ausgangspunkt aller späteren Fassungen wurden, berücksichtigt sind. Nun, Tristan wird im Unglück geboren; sein Vater ist gerade gestorben und seine Mutter Blanchefleur überlebt seine Geburt nicht. Daher der Name des Helden und die finstere Farbe, in die sein Leben getaucht ist. Blanchefleurs Bruder, der König Marke von Cornwallis, nimmt das Waisenkind in seinen Hof auf und zieht es groß. Tristans Sieg über den Riesen Morholt ist seine erste große Heldentat. Der Kampf gegen ihn nimmt einen nicht unbeträchtlichen Teil der Überlieferung ein. Doch Tristan erleidet dabei einen Streich durch ein vergiftetes Schwert. Ohne Hoffnung, je wieder zu genesen, besteigt Tristan aufs Geratewohl ein Schiff ohne Segel und Ruder; Seine einzigen Begleiter sind sein Schwert und seine Harfe. So gelangt er an die irische Küste.

Tristan ist in einer verzweifelten Lage. Allein die Königin von Irland kennt das Geheimnis, das den jungen Helden vor den Folgen des vergifteten Schwertschlages retten kann. Denn der Riese Morholt war kein anderer als ihr Bruder; und so muss sich Tristan hüten, seinen Namen und die Ursache seiner Erkrankung einzugestehen. Die schöne Isolde, die königliche Prinzessin, pflegt und heilt ihn; Tristan kehrt nach Cornwall zurück. Soweit der Prolog.

Einige Jahre später beschließt König Marke, jene Frau zu heiraten, von der ein Vogel ihm ein goldenes Haar gebracht hatte. Kurz entschlossen schickt er den jungen Tristan auf die Suche, und der Sturm treibt den Helden wiederum zur Insel Irland. Dort kämpft er mit einem Drachen, der die Hauptstadt bedroht, und tötet ihn. Wir haben es mit dem Motiv der von einem Ritter befreiten Jungfrau zu 
tun, das recht geläufig ist. Doch Tristan wurde von dem Ungeheuer verwundet und erneut von Isolde gepflegt - die Dinge wiederholen sich. Eines Tages jedoch entdeckt die schöne Prinzessin, dass der von ihr Gepflegte niemand anders als der Mörder ihres Onkels ist. Sie ergreift Tristans Schwert und droht, ihn im Bade zu töten. Da entdeckt er den Auftrag, den er von König Marke erhalten hat, die Frau mit den goldenen Haaren $\mathrm{zu}$ ihm zu bringen. Isolde lässt Gnade walten, denn sie hegt den verständlichen Wunsch, Königin zu werden.

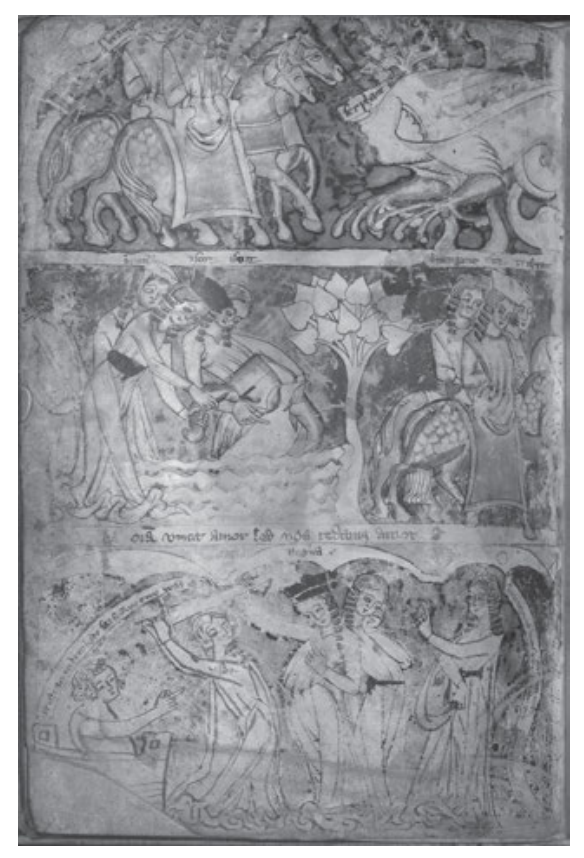

Abb. 43a: Miniatur aus Tristan und Isolde des Gottfried von Straßburg mit der Fortsetzung des Ulrich von Türheim, folio 67v.

In einigen Fassungen des Tristan-Mythos bewundert sie aber auch die Schönheit des jungen Tristan. Alsbald sind Tristan und Isolde unterwegs zu König Marke. Doch auf ihrem Weg auf hoher See schläft der Wind ein und die Hitze wird alsbald drückend. Durch einen Irrtum schenkt ihnen die Magd Brangäne jenen Trank ein, der von der Mutter für die künftigen Ehegatten vorgesehen war. Es ist das Motiv des Liebestrankes, der noch in jedem Hollywood-Film in verschiedenen Formen auftaucht. Isolde und Tristan sind auf dem Weg in ein Schicksal, das sie nie in ihrem Leben wieder freilässt, denn sie haben ihre Vernichtung und ihren Tod getrunken: Sie gestehen sich ihre Liebe und geben ihr nach. In einer Fassung des Mythos wird die Wirksamkeit des Liebestrankes auf drei Jahre beschränkt. Ein anderer Bearbeiter lässt aus Abneigung gegenüber dem Wunderbaren die 
Bedeutung des Liebestrankes in den Hintergrund treten und stellt die Liebe zwischen Tristan und Isolde als spontane Zuneigung dar, die bei der Szene im Bad zum ersten Mal in Erscheinung getreten sei. In der Mehrzahl der Bearbeitungen aber wird dem magischen Kräuterwein eine unbegrenzte Wirksamkeit zugeschrieben - und laut Denis de Rougemont ist nichts bedeutsamer als diese Variante, wie wir bei unserer Untersuchung noch sehen werden.

Der schöne und verliebte Tristan freilich bleibt durch seinen vom König empfangenen Auftrag gebunden; und so bringt er trotz ihres beiderseitigen Liebesverrates Isolde zu König Marke. Brangäne wird dem König durch eine List anstelle von Isolde während der Hochzeitsnacht zugeführt und rettet so ihre Herrin vor Schande, indem sie den verhängnisvollen Irrtum büßt, den sie begangen hat. Doch dem König wird durch einen Verräter die große Liebe zwischen Tristan und Isolde angezeigt. Tristan wird daraufhin verbannt. Doch durch eine neue List überzeugt er Marke von seiner Unschuld und kehrt an den Hof zurück. Der Zwerg Frocine, der es am Hofe mit den Adelsleuten hält, stellt den beiden Liebenden eine Falle, denn zwischen den Betten von Tristan und Isolde streut er Blüten von Getreide. Eine frische Wunde - wieder das Motiv der Verwundung - an Tristans Bein verrät ihn durch die Blutspuren auf den Getreideblüten. So ist der Beweis des Ehebruchs erbracht. Zur Strafe wird Isolde einer Aussätzigen übergeben, Tristan zum Tode verurteilt.

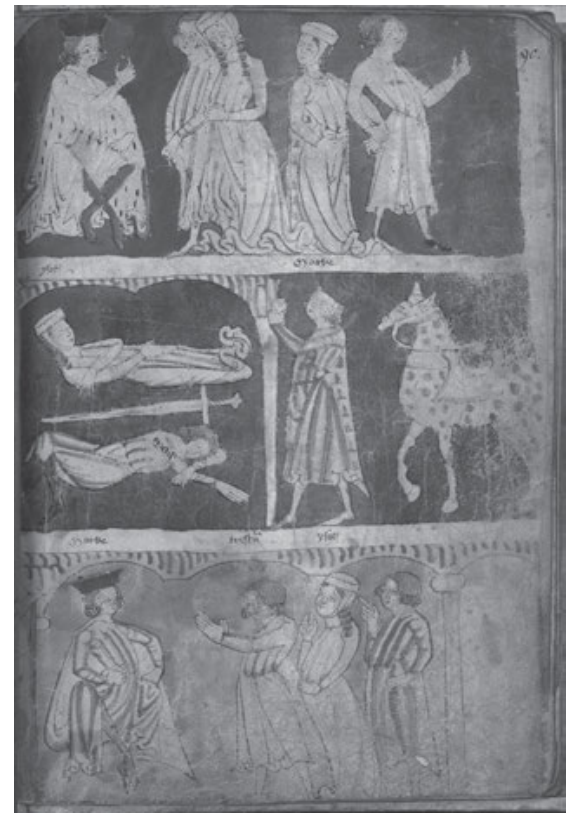

Abb. 43b: Miniatur aus Tristan und Isolde des Gottfried von Straßburg mit der Fortsetzung des Ulrich von Türheim, folio 90r. 
Doch er vermag zu entweichen und gelangt bei seiner Flucht in eine Kapelle. Er befreit die hoffnungslose Isolde und zieht sich mit ihr in den Wald von Morrois zurück, wo die ehemals glücklichen Liebenden ein graues, tristes und hartes Leben führen. Eines Tages entdeckt König Marke sie im Schlaf, und findet überrascht, dass Tristan sein blankes Schwert zwischen sich und Isolde gelegt hat als Zeichen der Keuschheit. Er erkennt dies als ein Zeichen an und begnadigt die beiden Liebenden. Ohne ihn zu wecken, nimmt der König Marke Tristans Schwert und legt sein königliches an die Stelle.

Nachdem drei Jahre verstrichen sind, hört der Liebestrank - so eine Fassung des Tristan-Mythos - auf zu wirken. Da erst beginnt Tristan, seine liebestrunkene Handlungsweise zu bereuen, und Isolde beginnt, sich nach dem Leben am Hofe von König Marke zu sehnen. Sie suchen den Einsiedler Ogrin auf, durch dessen Vermittlung Tristan dem König anbietet, ihm seine Frau zurückzugeben; Marke verspricht seine Gnade. Kann doch noch einmal das Geschehene zurückgedreht werden und alles in seine gesellschaftliche Ordnung zurückfinden? Die Liebenden trennen sich bei der Annäherung des königlichen Gefolges. Isolde bittet Tristan, im Lande zu bleiben, bis sie sicher sei, dass Marke sie gut behandelt. Die Kautele ist gefährlich: Auf das erste Zeichen hin werde sie wieder zu Tristan zurückkommen, ohne dass sie etwas zurückhalten könnte, weder Turm noch Mauer noch Festung. Es handelt sich um eine Art Reisekostenrücktrittsversicherung. Sofort nach ihrer Ankunft bei Hofe fordern die verräterischen Adelsherren einen Tugendbeweis von der zurückgekehrten Königin. Sie erbittet daraufhin ein Gottesurteil, um ihre Unschuld zu bezeugen.

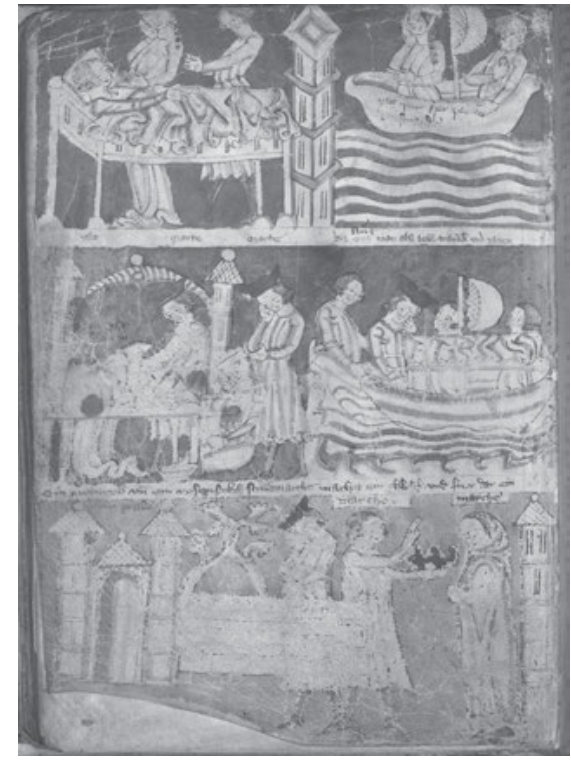

Abb. 43c: Miniatur aus Tristan und Isolde des Gottfried von Straßburg mit der Fortsetzung des Ulrich von Türheim, folio $107 \mathrm{v}$. 
Dank einer Ausflucht und List gelingt ihr letztlich dieser Beweis. Sie schwört, niemals in den Armen eines anderen Mannes gelegen zu haben als in jenen des Königs und des Bauern, der ihr aus dem Schiffe geholfen habe. Doch letzterer ist niemand anders als der verkleidete Tristan. Tristan glaubt anscheinend nicht mehr an Isoldes Liebe und willigt ein, eine andere Isolde jenseits des Meeres, Isolde mit den weißen Händen, um ihres Namens und ihrer Schönheit willen, zu heiraten. Doch im Grunde seines Herzens sehnt er sich noch immer nach seiner Isolde Goldhaar, die nun wieder Königin ist. Erneut zu Tode verwundet, lässt Tristan die Königin von Cornwallis rufen, denn sie ist die einzige, die ihn noch retten kann. Ein weißes Segel sollte das vereinbarte Zeichen ihres Kommens sein. Doch dann kündigt ein schwarzes Segel die Rückkehr des nach England entsandten Schiffes an: Tristan ist nun unrettbar dem Tode geweiht und stirbt. Isolde kommt auf das Schloss und umarmt ihren geliebten Toten.

Soweit also der Tristan-Mythos in seiner groben Darstellung, die ich Ihnen etwas ausführlicher nacherzählt habe, weil wir gleich nach Rougemont den Tristan-Mythos noch einmal in einer neueren Version kennenlernen werden. Der Schweizer Essayist und Literat hob in L'amour et l'Occident hervor, dass dieser Mythos von einem langanhaltenden und die Liebeskonzeptionen des Abendlandes wesentlich mitprägenden Einfluss gewesen sei, und dass er auch weiterhin noch wirke. Dafür werden wir im weiteren Fortgang unserer Vorlesung ein literarisches Beispiel aus dem transkulturellen Bereich wählen und erneut in das westöstliche Spannungsfeld der Argumentation von Denis de Rougemont stellen.

Ich würde Ihnen an dieser Stelle gerne eine der berühmtesten Szenen einer Bearbeitung des Tristanstoffes zu Gehör bringen, und zwar die Schlussszene des dritten Aufzugs von Richard Wagners Oper Tristan und Isolde. Der „Tristan“ ist von Wagner im Sommer 1857 begonnen worden und war Anfang August 1859 fertig komponiert, wurde jedoch erst am 10. Juni 1865 in München aufgeführt. Dies geschah kurz nach der großen Wende in Wagners Leben, als ihn der bayerische König Ludwig II. 1864 dorthin holte. Die Schwierigkeiten auf Grund der hohen Anforderungen an die Sänger waren so beträchtlich, dass ein früherer Aufführungsversuch in Wien wieder abgebrochen werden musste. Wagners Kunstkonzeptionen holten auch noch das Letzte aus den Darstellern und Musikern heraus. Der kubanische Romancier und Musiksachverständige Alejo Carpentier witzelte einmal, in Lateinamerika gehe den Wagner-Aufführungen immer ein Rattern und Sägen voraus, weil man überall den Raum für das Orchester vergrößern müsse. Doch Richard Wagner war auch durch die Wiener Erfahrung nicht mehr aufzuhalten: Er war von seinem Werk überzeugt, sei es doch mehr Musik als alles, was er zuvor je geschrieben habe.

Hören Sie nun die Schlussszene, das Zusammensinken Isoldes über dem Leichnam ihres Tristan, in einer Einspielung von Georg Solti mit den Wiener Philharmonikern von 1961, wobei den Part Isoldes Birgit Nilsson singt. Wir setzen 
etwas abrupt in der Schlussszene ein, nachdem Brangäne ihre Herrin Isolde fragt, ob sie denn nicht höre, ob sie nicht die Treue vernehmen könne:

Isolde, die nichts um sie her vernommen, heftet das Auge mit wachsender Begeisterung auf Tristans Leiche.

ISOLDE. Mild und leise / wie er lächelt, / wie das Auge / hold er öffnet - / Seht ihr's, Freunde? / Seht ihr's nicht? / Immer lichter / wie er leuchtet, / Stern-umstrahlet / hoch sich hebt? / Seht ihr's nicht? / Wie das Herz ihm / mutig schwillt, / voll und hehr / im Busen ihm quillt? /

Wie den Lippen, / wonnig mild, / süßer Atem / sanft entweht? / Freunde! Seht! / Fühlt und seht ihr's nicht? - / Höre ich nur / diese Weise, / die so wunder- / voll und leise, / Wonne klagend, / Alles sagend, / mild versöhnend / aus ihm tönend / in mich dringet, / auf sich schwinget, / hold erhallend / um mich klinget? / Heller schallend, / mich umwallend, / sind es Wellen / sanfter Lüfte? / Sind es Wolken / wonniger Düfte? /

Wie sie schwellen, / mich umrauschen, / soll ich atmen, / soll ich lauschen? / Soll ich schlürfen, / untertauchen? / Süß in Düften / mich verhauchen? / In dem wogenden Schwall, / in dem tönenden Schall, / in des Welt-Atems / wehendem All -, / ertrinken, / versinken -, / unbewußt -, / höchste Lust!

Isolde sinkt, wie verklärt, in Brangänes Armen, sanft auf Tristans Leiche. - Große Rührung und Entrücktheit unter den Umstehenden. - Der Vorhang fällt während der letzten Fermate. ${ }^{8}$

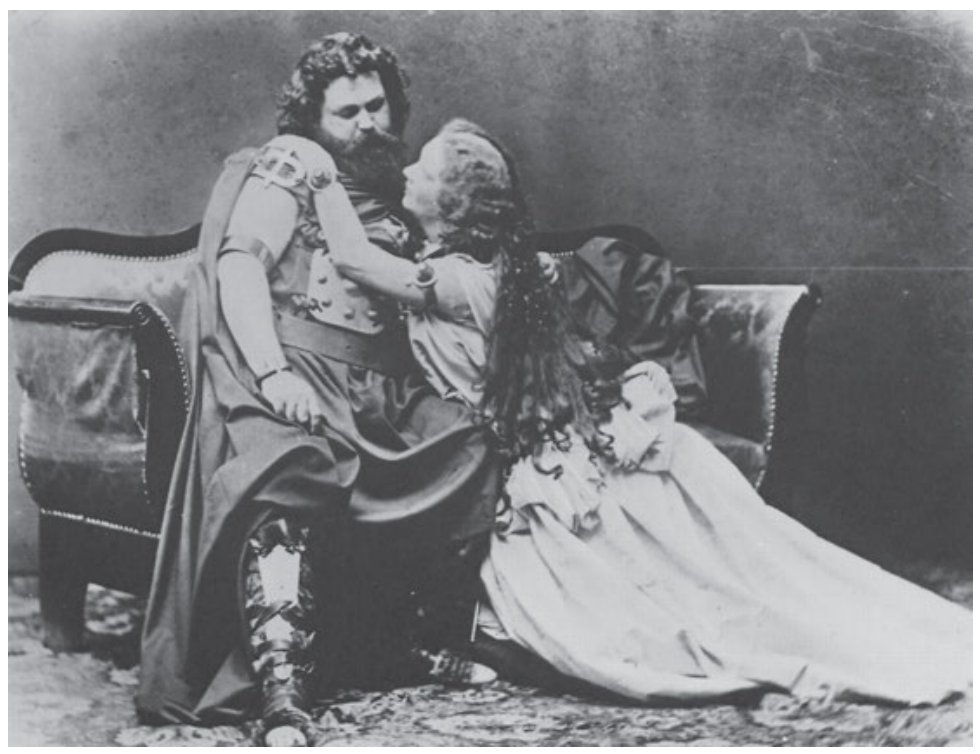

Abb. 44: Ludwig und Malwine Schnorr von Carolsfeld als Tristan und Isolde in der Münchner Uraufführung, Fotografie von Joseph Albert, 1865.

8 Wagner, Richard: Tristan und Isolde, Dritter Aufzug. 
Sie merken, wie die Lust noch jeden Schmerz tief durchdringt und ihm letztlich seinen Seinsgrund vermittelt. Liebe erscheint als eine Leidenschaft, die Leiden schafft, aber von höchster Lust durchdrungen ist - bis zum Tode. Es gibt vor allem zwei Quellen, die zu Richard Wagners Oper Tristan und Isolde geführt haben. Zum einen handelt es sich dabei um Gottfried von Straßburgs Epos Tristan und Isolt (1210), und zum anderen die Tragödie mit dreiundzwanzig Personen von der strengen Lieb’ Herrn Tristans mit der schönen Königin Isolden (1553) von Hans Sachs. Seit 1854 beschäftigte sich Richard Wagner mit diesem Stoff für ein Liebesdrama, wie er an Franz Liszt schrieb, und zwar vor dem Hintergrund der Bekanntschaft, die er mit der Philosophie Schopenhauers gemacht habe. So spitzte sich der Mythos von Tristan und Isolde, gleichsam im Lichte Schopenhauers, romantisch zu einem Gesamtkunstwerk zu.

Die sich die gesamte Oper über steigernde Ekstase des Liebespaares findet in einer Musik ihre Entsprechung, die an die Grenzen der Tonalität stößt. Hinzu aber kommt auch eine besondere, übersteigert wirkende Sprache, die den seelischen Vorgängen - wie wir sahen - den größten Platz einräumt und hierin die Handlung kulminieren lässt. Bei Wagner lieben sich Tristan und Isolde von Anfang an, und der Trank bildet nur ein äußeres Symbol für die Überwindung auch noch der letzten Hemmnisse. Achten Sie einmal darauf, wie häufig dieses alte Motiv selbst in der Gegenwartsliteratur erscheint. Von Schopenhauers Thesen beeinflusst, schuf Wagner hier eine expressive Ausdrucksform des Mythos von der ausweglosen, tödlichen Liebe, wobei jegliche Art äußerlicher Handlung bei Wagner auf ein Minimum beschränkt blieb. Alles wird nach innen geblendet: Selbst der tote Tristan scheint in den Augen Isoldes noch zu leben und $\mathrm{zu}$ atmen.

Doch kehren wir wieder zu Denis de Rougemont und seiner Analyse abendländischer Liebe in L'amour et l'Occident zurück. Im Grunde ließe sich sein gesamter Band als ein einziger gewaltiger Kommentar zu Richard Wagners Tristan und Isolde lesen, denn der Schweizer Essayist, der in den dreißiger Jahren in Frankfurt am Main die Entwicklungen innerhalb der immer nationalsozialistischer werdenden Romanistik und Universitätslandschaft aus nächster Nähe verfolgt hatte, erläuterte in großer Breite jene Traditionslinien und Quellen, aus denen sich auf direkte oder vielfach vermittelte Weise die Wagner'sche Oper speist. Dabei sieht Rougemont das 12. Jahrhundert als die entscheidende Phase innerhalb der abendländischen Liebesauffassung an. Zugleich wird dieses 12. Jahrhundert zu einem herausragenden und bis in die Gegenwart hinein wirksamen Wendepunkt innerhalb der Herauskristallisierung dessen, was wir als das Abendland oder den Okzident beschreiben können. Dies bedarf einer Erläuterung.

Der für diese Entwicklung entscheidende Schlüssel ist für Rougemont die höfische Liebe. Sie besitzt eine klare Stoßrichtung gegen die christliche Agape und insbesondere gegen die christliche Institution der Ehe, gegen die sich auch 
später Immanuel Kant verwehren sollte als jene Institution, die den wechselseitigen Gebrauch der Geschlechtsorgane regelt und gesellschaftlich normalisiert. Die Konzeption des Rittertums wendet sich gerade gegen jenen Aspekt einer Regelung der Affekte in einer normalisierten Geschlechterbeziehung, aus der die Leidenschaft und Leidenschaftlichkeit ausgebürgert wurden. Dabei ging der Verfasser von Die Liebe und das Abendland zugleich davon aus, dass nur im Kontext der höfischen Liebe jene Troubadour-Lyrik entstehen konnte, die alle spätere Lyrik im Abendland prägen sollte. Denn für Rougemont geht jegliche spätere Dichtung auf die Troubadour-Lyrik und damit zuletzt auch auf deren Sprache zurück.

Gewiss, eine solche Sichtweise argumentiert recht monokausal. Nicht umsonst hatte Rougemont im Vorwort gewarnt, dass ein Buch möglichst nicht die Komplexität des Lebens erreichen sollte. Aber die Argumentation des Schweizers ist in ihrer Stringenz durchaus bestechend. Das Rittertum mit seiner Vasallenschaft gegenüber dem Lehensherrn übertrug laut Rougemont diese soziale Konzeption auf die geliebte und idealisierte Frau, auf die belle dame sans merci, die schöne Frau ohne Gnade, die wir später noch als eine Konstante durch die Literaturgeschichten - etwa bei Balzac oder im Fin de siècle - geistern sehen werden. Das Motiv der femme fatale ist hier nicht weit entfernt, sondern leitet sich in der Argumentation von Rougemont direkt aus dieser Traditionslinie ab.

Damit stehen sich im Abendland letztlich zwei Liebeskonzeptionen gegenüber, die sich in der Tat durch die nachfolgenden Jahrhunderte hindurch gerade in der Literatur, aber ebenso in den Künsten allgemein verfolgen lassen. Überdeutlich ist, dass die Liebe, um die es Denis de Rougemont geht, jene der später von Stendhal so bezeichneten amour-passion ist, und diese leidenschaftliche Liebe sich ihrerseits aus Quellen speist, die einer spezifischen gesellschaftlichen Konstellation - der des Rittertums - und einer weiteren Traditionslinie entstammen, die man zunächst grob als eine religiöse bezeichnen könnte. Mit der letzteren Liebeskonzeption ist zugleich eine Liebe nicht notwendig zum Anderen, sondern vor allem zur Liebe selbst verbunden, wobei der Verfasser von L'amour et l'Occident auf das berühmte Wort von Augustinus verweist, der die Liebe zur Liebe selbst und nicht zum Geliebten festhält.

Dabei handelt es sich um das berühmte amabam amare, auf das wir im Grunde schon bei Roland Barthes gestoßen waren, und das sich im TristanMythos ebenso unverhohlen ausspricht: die Liebenden sind jeweils in sich gefangen. Denn hier können gute Gründe dafür ins Feld geführt werden, dass Tristan im eigentlichen Sinne nicht in erster Linie seine Geliebte liebt, sondern seine Liebe zur Geliebten. Von daher bedarf Tristan auch nicht ihrer Präsenz, ihrer Gegenwart, sondern braucht im Wesentlichen ihre Abwesenheit und das Unglück der Liebe selbst. Diese unglückliche Liebe wiederum entzündet die Fähigkeit zur vorrangigen Betrachtung der eigenen Liebe und verstärkt diese Liebeskonzeption 
wie in einer Endlosschleife. So zeigt sich hier eine weitere Dimension dieser Liebespraxis, nämlich die einer Liebe, die im Grunde nur eines fernen, ja fast unerreichbaren Liebesobjekts bedarf, einer Liebe, die aber implodieren würde, sobald sich dieses Liebesobjekt annähern und dauerhaft zur Verfügung stehen würde. Im Angesicht eines erreichbaren Liebesobjekts würde diese Liebe, die auf die Selbstliebe gerichtet ist, erlöschen oder zugrunde gehen.

Innerhalb dieses gedanklichen Horizonts aber wird nach Rougemont die Liebe nicht auf das Leben, sondern auf den Tod gerichtet. Dies ist eine Verbindung von Eros und Thanatos, auf die wir immer wieder stoßen werden und die im Grunde eine zentrale Dimension der abendländischen Liebeskonzeption ausmacht, lange vor Goethes Werther und den von diesem Roman ausgelösten Selbstmordwellen. Damit ist die Sprache der Liebe als Sprache der Leidenschaft auch eine Sprache, die am Leiden Gefallen findet und sich letztlich nach dem Tode sehnt, da die Lehnsherrin, deren Vasall der Ritter ist, letztlich unerreichbar und die Liebe des Troubadours unerfüllt bleibt. Die Kodierung dieser Sprache ist dabei unverkennbar eine religiöse.

Aufschlussreich ist, wie stark Denis de Rougemont diesen Diskurs der abendländischen Liebe mit Traditionen verbindet, die gleichsam weltweit verlaufen, insbesondere aber die Beziehungen zwischen Abendland und Morgenland hervorheben:

Die höfische Liebe ist im zwölften Jahrhundert inmitten einer Revolution der abendländischen Psyche entstanden. Sie ist aus derselben Bewegung hervorgegangen, die das Weibliche Prinzip der Shakti, den Kult der Frau, der Mutter und der Jungfrau in das Halbdämmern des Bewusstseins und des lyrischen Seelenausdrucks aufsteigen ließ. Sie nimmt teil an jener Epiphanie der Anima, die in meinen Augen die Rückkehr eines symbolischen Morgenlandes im abendländischen Menschen darstellt. Sie wird uns verständlich durch gewisse historische Marksteine: durch ihre Verbindung mit der zur gleichen Zeit entstandenen Häresie der Katharer und durch ihren versteckten oder offenen Gegensatz zur christlichen Eheauffassung. Sie wäre uns vollkommen gleichgültig, hätte sie nicht durch zahlreiche Wiedergeburten hindurch, deren Verlauf wir noch zu beschreiben haben, in unserem Leben ein geheimes, stets wieder neues Gift hinterlassen. ${ }^{9}$

Am Ausgang dieser Passage ist das Lexem „Gift“ gewiss in seiner Doppelbedeutung zu verstehen als ein pharmakon, das als Arzneimittel stets je nach Dosierung entweder heilende oder schädliche Wirkungen zeitigt. Es ist gleichsam beides in einem. Dieses Gift ist im deutschen Sinne eine Vergiftung der Beziehungen zwischen den Geschlechtern, aber zugleich im englischen Sinne eine Gabe, die den beiden Geschlechtern zur Verfügung steht. Wir sind nun fast schon in der

9 De Rougemont, Denis: L'amour et l'Occident, S. $135 \mathrm{f}$. 
Lage, diese Überlegungen Rougemonts vollständig zu verstehen. Deutlich ist uns freilich bereits jetzt die Tatsache, dass Rougemont die aktuellen Liebeskonzeptionen rückgebunden sieht an jene Konzeption der Liebe, welche im Umfeld der höfischen Liebe die Liebe als Leidenschaft zelebrierte und in unterschiedlichsten Formen sehr subtil und kodifiziert entwickelte. Nun aber benötigen wir noch ein entscheidendes Verbindungsstück, um die Gedanken des Schweizer Essayisten vollständig zu begreifen.

Dazu müssen wir etwas in die Geschichte der sogenannten Häresien und ihrer blutigen Unterdrückung im Abendland eintauchen. Als Bernard de Clairvaux im Jahre 1209 den Kreuzzug gegen die Katharer predigte, begann das blutige Ende einer Entwicklung heraufzuziehen, die von der katholischen Kirche und ihrer Inquisition seit langem argwöhnisch und mit wachsender Sorge beobachtet worden war. Die Häresie der Katharer, die sich wohl ursprünglich im bulgarischen Raum entwickelte, hatte sich in verschiedene andere Regionen Europas hin ausgebreitet, darunter sowohl nach England als auch in den Süden Frankreichs. Zum Zentrum der Katharer waren der Languedoc, die Grafschaft Toulouse und vor allem die Stadt Albi geworden, die in der Folge zum Sinnbild der gesamten Bewegung, und damit auch zum Ziel der Kreuzzüge der sogenannten Albigenserkriege wurde. Wenn Sie diese wunderschöne Stadt - Albi, la pourpre - im Süden Frankreichs heute besuchen, dann werden sie noch unschwer die Spuren dieser Albigenserkriege vorfinden.

Die Katharer, abgeleitet aus dem griechischen Wort für „rein“, verstanden sich als eine Kirche der Liebe, in der eine strenge Trennung zwischen den „perfecti“, den Vollkommenen, und den gemeinen Gläubigen herrschte. Während letztere sich in der Welt und auch in der Geschlechtlichkeit einrichten konnten, war es den erstgenannten untersagt, Beziehungen zu Frauen zu unterhalten. Denis de Rougemonts These nun ist, dass die Troubadoure und die Konzeption der höfischen Liebe, der „cortesia“, ohne die Entwicklung der häretischen Katharer gar nicht möglich gewesen wäre, ohne dass man deswegen die Troubadoure gleichsam als Sänger der Häresie verstehen müsste. Aber in ihnen kommen Liebeskonzeptionen zum Ausdruck, welche die Dimension der Leidenschaft und der Unerreichbarkeit der hochgestellten Frauen beinhalten und in scharfem, schroffem Gegensatz zur Institution der Ehe im Sinne der machtvollen katholischen Kirche stehen. Vielleicht sind uns aufgrund dieser Liebeskonzeptionen auch die albigensischen Häretiker stets in der Geschichte Frankreichs sympathisch geblieben. Fakt ist, dass die Kirche gegen die Anhänger dieser Liebeskonzeptionen mobil machte und schließlich zu einem Kreuzzug rief, der in einem grauenhaften Blutbad endete.

Wir sehen hier erstmals in der Geschichte eine zentrale Verbindung zwischen Liebe und Häresie, zwischen Liebesleidenschaft und religiösem, abweichlerischem Eifer, der institutionsgefährdend und subversiv sein kann. Mit der radikalen Zerstörung der Kultur der Katharer, der rücksichtslosen Vernichtung ihrer 
Schriften durch die Inquisition und all jenen Gräueltaten, die Rougemont als den ersten geplanten Genozid des christlichen Abendlands bezeichnete, wird freilich nicht die Liebesauffassung im Kontext weiterer Elemente dieser Kultur zerstört. Vielmehr findet diese in einem sehr breiten Maße Eingang in die Konzeptionen des Abendlandes überhaupt. Liebesvorstellungen sind so einfach nicht zu bekriegen und zu unterwerfen.

In diesem Zusammenhang sprach Denis de Rougemont auch von „Eros und dem Begehren ohne Ende“, ${ }^{10}$ insoweit die Entrückung des Liebesobjekts es ermöglicht, die Liebe gleichsam zu einer Leidenschaft ohne konkretes Ziel und letztlich auch ohne ein Ende zu stilisieren. Allein im Zusammenspiel von Rittertum und Katharer-Häresie entwickelt sich gleichsam jener Treibsatz leidenschaftlicher und unglücklicher Liebe, der - so Denis de Rougemont - erstmals im berühmten Liebespaar Eloïse und Abélard im 12. Jahrhundert zum Ausdruck kam. Aber auch der Tristan-Mythos selbst stellt das vielleicht nachhaltigste und zugleich anschaulichste Zeugnis der künstlerisch machtvollen Entwicklung dieser Liebeskonzeption dar. Denn in der Kultur kann sehr wohl fortleben, was im Krieg bekämpft und scheinbar zerstört worden ist.

Vor diesem historischen Hintergrund und aus dieser spezifischen Perspektivik wird verständlich, warum die christliche Mystik hier nun eine wesentliche Brückenfunktion übernimmt und ihr ein derartiges Gewicht zukommt. Denn Mystiker wie Ruysbroek oder Meister Ekkehardt (auf die wir bereits bei Roland Barthes in seinen Fragments d'un discours amoureux gestoßen waren), insbesondere aber auch die Spanier San Juan de la Cruz oder Santa Teresa de Avila verbinden diese christlichen Auffassungen mit Traditionen, die ganz ohne Zweifel aus dem arabischen Raum und von muslimischen Mystikern stammen.

Diese Situation des 16. Jahrhunderts, die ganz grundlegend die christliche Liebeskonzeption in den Bannkreis einer Vereinigungssehnsucht rückte, drückt sich in wunderbarer Weise in der mystischen Literatur der Heiligen Teresa von Avila, wie beispielsweise ihren Moradas, aus. Es sind Vorstellungen der durchaus erotischen Vereinigung mit Christus, der sogenannten unio mystica, die eine Lexik geprägt haben, welche direkt auch auf unsere Liebesbegrifflichkeiten erheblichen Einfluss nahmen. Wenn wir im 21. Jahrhundert von der Liebe reden, so spricht in uns noch immer etwas von dem, was im 12. wie im 16. Jahrhundert gedacht und gesprochen wurde. Nicht umsonst kommt der Begriff der Mystik aus dem Griechischen und ist mit dem Schließen der Augen verbunden.

Die christlichen Liebesvorstellungen, welche auch auf andere Quellen, vor allem aber auf leidenschaftlich-mystische Konzeptionen von Liebe in einer

10 De Rougemont, Denis: L'amour et l'Occident, S. 61. 
geradezu tantrischen Vereinigung mit Gott verweisen, greifen letztlich zurück auf jenen gewaltigen Einfluss der arabischen Mystiker und Sufis. Sie gewannen auf die abendländischen Mystikerinnen und Mystiker so starken Einfluss, dass von einer klaren Trennung zwischen Ost und West, zwischen Abendland und Morgenland nicht mehr die Rede sein kann. Denis de Rougemont verfolgt diese Traditionen zurück bis in jene Entwicklung von Sekten, die sich etwa im Tantrismus, aber auch in anderen Formen ebenso spiritueller wie physischer Liebe entwickelten.

Der Hinweis auf die Shakti im obigen Zitat verweist zweifellos auf den Tantrismus, der in Shakti die geheime Kraft anbetete, welche den Kosmos belebt und die Götter erhält, an erster Stelle Shiva und Buddha. Einen westlichen Abklatsch finden wir in zahlreichen Veröffentlichungen zum Tantra der Liebe, das für eine westliche Leserschaft auf bestimmte praktikable Liebesstellungen reduziert wird. Das Spirituelle flüchtet sich dabei zumeist ins Vor- oder Nachwort. Auch auf diese Weise wird die Liebe mit dem Lesen verbunden.

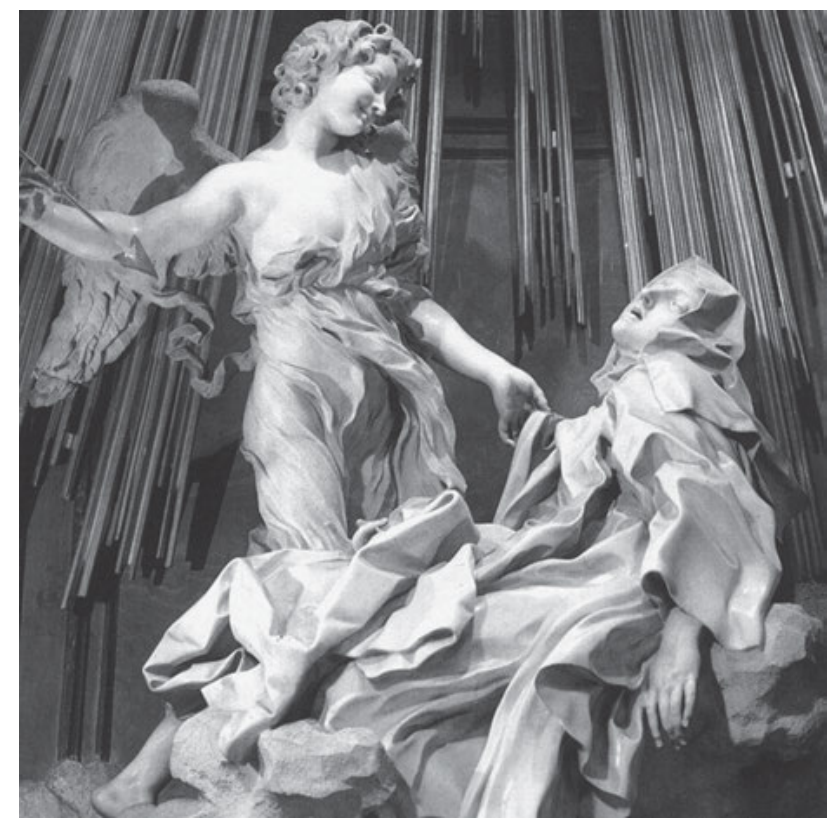

Abb. 45: „Die Verzückung der heiligen Theresa“, Frontalskulptur von Gian Lorenzo Bernini, 1645-1652 (Detail).

An dieser Stelle wird deutlich, dass der Tantrismus, der in regelmäßigen Abständen im Abendland bekannt wurde, Eingang in esoterisches Wissen fand und ab dem 20. Jahrhundert als Liebestechnik im Westen vermarktet wurde. Doch er 
entwickelte eine Konzeption der Liebe, welche letztlich auf die Erkenntnis des Lebens und die Erkenntnis der Welt hinausläuft. Tantra wird heutzutage im Westen bestenfalls als eine Kunst der Liebe verstanden, wobei die spirituellen und mystischen Hintergründe dieser ursprünglich in Indien entwickelten tantrischen Lehre durchaus bewusst aus dem Blickfeld gerieten. Tantra heißt nämlich zunächst „Fäden“ oder „Gewebe“ - also gar nicht so weit vom Lesen und von unserer Textmetaphorik entfernt. Es bedeutet zugleich aber auch „innerstes Wesen“ oder „Essenz“.

Tantra zielt nicht auf die sexuelle Vereinigung, für die es bestimmte Stellungen entwickelt hat, sondern versucht, durch die sexuelle Vereinigung neue spirituelle Räume der Begegnung und den Erfahrung zu öffnen, sie für ein vollständiges Erleben den Liebenden zugänglich zu machen. All diese Vorstellungen stammen ursprünglich aus der geistigen Welt von Hinduismus und Buddhismus; die einzelnen Traktate oder Schriften, die diese tantrischen Schulen entwickelten, nannte man einfach Tantras. Sie dokumentieren den Dialog zwischen der männlichen Gottheit Shiva und seiner Geliebten Parvati; und aus beider Vereinigung entsteht ein ganz bestimmtes Wissen über die Liebe, über die Welt und über den Kosmos, das in den Tantras gesammelt und den Eingeweihten zur Verfügung gestellt wurde.

In einer Reihe von Dialogen klärt die männliche Gottheit Shiva - und sie bemerken ohne weiteres die patriarchale Ausrichtung - seine göttliche Gefährtin, die eine Personifizierung Shaktis ist, über die Bedeutungen der Liebe und des Kosmos auf. Die Ursprünge des tantrischen Wissens gehen wahrscheinlich bis in die Anfänge der Hochkulturen matriarchaler Zivilisation vor mehr als zehntausend Jahren zurück, bilden also einen uralten Lehrkörper, demgegenüber sich unser Christentum als eine sehr späte Entwicklung erweist, die gleichwohl noch älter als der Islam, aber deutlich jünger als das Judentum ist. Ich kann an dieser Stelle nicht auf die unterschiedlichen Schulen des Tantrismus eingehen, sondern will Ihnen nur einige grobe Züge vermitteln.

Es sei zumindest festgehalten, dass im Zentrum aller Schulen die Suche nach der Einheit - wie in allen östlichen Philosophien und Religionen -, nach Harmonie, Balance und Ausgleich steht. Die tantrische Schöpfungsgeschichte geht dabei von einer Urgöttin und damit von einem weiblichen Prinzip als Ausgangspunkt aller Kraft und aller Schöpfung aus. So verwundert es auch nicht, dass die Urgöttin an erster Stelle nicht einen Mann, sondern zunächst eine Frau schuf und dann erst den Mann. Von Beginn an kommt dabei dem Schöpfungsund Zeugungsakt eine zentrale Erkenntnisfunktion zu, so dass auch im Weiteren die Sexualität stets eingebunden ist in eine Gesamtheit schöpferischer Energien und Erkenntnisformen. Dass sie auch in den abendländischen Traditionen nicht einfach eine davon abgetrennte Funktion ist, sondern ihr auch eine grundlegende 
Erkenntnis- und Selbsterkenntnisfunktion zukommt, haben wir bei unserem Baron auf den Bäumen mit Italo Calvino gesehen. Freilich haben wir durchaus zu beklagen, dass es im Westen nur mehr eine Art Schwundstufe ist, die von dieser Erkenntnisfunktion übrig geblieben ist. Und doch ist sie vorhanden.

Die kosmische Dimension der Liebe wird anhand dieser Zusammenhänge deutlich: Hier geht es um eine Vereinigung nicht nur im körperlichen Sinne, sondern mit einem Ur-Einen, in dem sich das einzelne Individuum verliert. Um diese Erkenntnis zu erlangen, sind bestimmte Techniken notwendig. Dabei ist die Rolle der Frau, so scheint mir, eher die eines Mediums und letztlich eines Objekts, das den Zugang zu dieser Erkenntnis erlaubt oder öffnet. Ohne in dieser Argumentation auf größere Kenntnisse des Tantrismus und des Tantra der Liebe zurückgreifen zu können, sei doch festgehalten, dass die körperliche Liebe - das, was wir in der griechischen Tradition als Eros beschreiben - eine hochgradig spirituelle Dimension entfaltet, insoweit sie uns Zugang zum Wissen über den Kosmos verschafft, und damit natürlich über die höchste Form des Lebenswissens überhaupt.

Klar ist dadurch auch, dass Liebe sehr oft - oder vielleicht sogar immer? die Dimension des Kosmischen beinhaltet. Sie wissen, dass in dem griechischen Begriff Kosmos zwei Dimensionen zusammengebunden und zusammengeführt werden: erstens die Dimension der Ordnung, des Geordneten, das dem Chaos gegenübertritt; und zweitens die Dimension der Schönheit, des Ästhetischen also, die mit dieser Ordnung einhergeht. Noch in unserem Begriff der „Kosmetik“ wird diese Verbindung deutlich, wird doch eine „Ordnung“ etwa im Gesicht hergestellt, die zugleich und vor allem auf das Ästhetische und die Herstellung von Schönheit abzielt. Insofern sind selbst hier noch beide Dimensionen enthalten, auch wenn der zentrale Aspekt des Zugangs zur Erkenntnis größtenteils aufgegeben wurde denn nicht selten soll durch Kosmetik ja gerade das Problematische und Fehlerhafte ausgeglichen werden, also eine Art Oberflächenkosmetik betrieben werden.

Der Tantrismus beinhaltet durchaus eine dienende Funktion des Mannes gegenüber der verehrten Frau, eine offenkundige Parallele zur Konzeption des Rittertums und der höfischen Liebe, die wir noch in Cervantes' Don Quijote in dessen Liebe zur unerreichbaren Dulcinea in all ihrer Stärke, aber auch in ihrem abgründigen Aspekt karikiert finden. Das Dienen erlaubt dem Manne gleichzeitig über einen langen Zeitraum der Annäherung eine zunehmende Besitzergreifung der Frau anzuvisieren oder in die Wege zu leiten. Damit verbindet sich zugleich eine Annäherung an die Erkenntnis, an das weibliche Prinzip und damit an ein Naturprinzip, wobei dieser binäre Schematismus in unserer abendländischen Kultur eine grundlegende Bedeutung entwickelt hat. Selbstverständlich haben wir es wohl selbst im Sinne von Judith Butler nicht mit dem „biologisch“ verankerten sex, der für die US-amerikanische Philosophin ohnehin zu dekonstruieren 
und aufzulösen ist, sondern mit gender in einem rein kulturellen Sinne zu tun, wie er unsere kulturell konfigurierten Geschlechtlichkeiten durchdringt.

In diesem durch Kultur definierten und bestimmten Bereich sieht Denis de Rougemont auch den Anknüpfungspunkt einer Verbindung der Liebeskonzeptionen jenseits allzu einfacher und schematischer Trennungen zwischen Ost und West, zwischen Abendland und Morgenland. Wir beginnen zu begreifen, dass beide Kulturen nicht einfach voneinander $\mathrm{zu}$ trennen sind, sondern dass wir das Morgenland im Abendland, den Orient im Okzident seit jeher vorfinden. In diesem Zusammenhang sind es vor allem die Mittelmeerländer - und allen voran natürlich Spanien ${ }^{11}$-, aber eben auch der Midi, der Süden Frankreichs, die als wesentliche Vermittlungsräume für diese Lehren, Sekten und Häresien dienten. Vergessen wir dabei niemals, dass nicht allein die christlichen Mystiker von der Inquisition bedrängt waren, sondern auch und gerade die arabischen Sufis und Mystiker von jeher lebensbedrohlichen Verfolgungen ausgesetzt blieben. Die Konzeptionen der Liebe enthielten bei diesen Outlaws und Marginalisierten außerhalb der jeweils herrschenden Doxa stets auch genügend Sprengkraft, um den orthodoxen Vorstellungen im Bereich der Religion gefährlich werden zu können. Kein Zweifel: Liebe ist stets auch der Versuch einer Erkenntnisgewinnung, eines Vordringens zu einer Erkenntnis und Selbsterkenntnis, die uns ohne diese Erfahrung und ohne dieses Erleben nicht möglich wären. Ihre gesellschaftliche Sprengkraft sowie ihr Potential, gesellschaftsverändernd zu wirken, haben die verschiedenen Auffassungen von Liebe seit der Antike über das Mittelalter, bis hin zum Christopher Street Day stets unter Beweis gestellt.

All diese Konzeptionen und Praktiken stehen selbstverständlich in einem grundlegenden Gegensatz zur christlichen Auffassung von der monogamen Ehe, die im zwölften Jahrhundert in eine tiefe Krise stürzte. Auch hiergegen wandte sich der Kreuzzug der katholischen Kirche, wobei Bernard de Clairvaux freilich klug genug war, bestimmte mystische Dimensionen und nicht zuletzt auch die Rolle der Frau in seine Erneuerung des christlichen Glaubens miteinzubeziehen. Denn für die Katharer war die Frau - ähnlich wie in den einzelnen Schulen des Tantrismus - sowohl die Mutter als auch die Jungfrau, sowohl die Geliebte und Gattin als auch die Tochter, beinhaltete also alle Dimensionen des weiblichen Prinzips und nicht nur eine einzige Rolle und Funktion, die dann zum Objekt der Liebe und zugleich zum Liebesobjekt auserkoren werden kann.

Damit ist letztlich auch eine Sichtweise und eine Rolle der Frau entwickelt, die sich quer durch die patriarchalisch bestimmte Geschichte des Abendlandes

11 Vgl. hierzu Walter, Monika: Der verschwundene Islam? Für eine andere Kulturgeschichte Westeuropas. Paderborn: Wilhelm Fink Verlag 2016. 
ziehen wird. Das weibliche Prinzip scheint in den unterschiedlichsten Liebesfiguren noch durch, die uns in unserer Kultur von massenkulturellen Aufbereitungen und Variationen her vorgespiegelt und suggestiv vor Augen geführt werden. Dies ist genau das, was Denis de Rougemont als die verschiedenen Wiedergeburten dieser Liebeskonzeption, insbesondere auch unter der Form des Tristan-Mythos, bezeichnen wird. Noch in den Pornofilmen übelsten Zuschnitts können wir Elemente dieses Mythos erkennen, und sei es in jenem Trank, den die Liebenden vor dem Geschlechtsakt einnehmen, bevor sie sich in die Arme fallen. Denn nicht umsonst handelt es sich um eine Form der Inkorporation, die im Grunde die Verkörperlichung und Einführung vorwegnimmt, die schon immer im Liebestrank Tristans und Isoldes, des von der Mutter hergestellten und von der Magd Brangäne zur Verfügung gestellten Liebestrankes also, vorhanden war. Der Mythos erscheint oft dort, wo wir ihn gerade nicht vermuten würden. Und doch ist er da.

Damit haben wir nun jene Elemente versammelt, die es uns erlauben, die gesamte Tragweite der Konzeption Denis de Rougemonts $\mathrm{zu}$ verstehen und $\mathrm{zu}$ begreifen, dass die Konzeption leidenschaftlicher Liebe im Abendland das Ergebnis einer hochkomplexen inter- und transkulturellen Entwicklung war, die im zwölften Jahrhundert unter den Bedingungen von Rittertum und Häresie, von christlichen und arabischen Sekten, innerhalb eines geographischen und kulturellen Raumes entstand, der vom Iran und Irak bis ins arabische Spanien und in die arabisch mitgeprägten südlichen Teilen Frankreichs reichte. Wir befinden uns in einer Epoche - dies sollten wir nicht vergessen -, in welcher die größte Stadt Europas Córdoba, und die arabische Kultur der europäischen in den meisten Parametern überlegen war. In weiten Teilen Spaniens, selbst in den unterschiedlichen und von arabischen Herren dominierten Taifas, bildete die morgenländische Kultur die Spitze einer verfeinerten Zivilisation innerhalb der Grenzen dessen, was wir heute als Europa begreifen.

Dies ist die arabische Dimension des Abendlandes, die allzu viele so gerne aus all unseren Identitätskonzeptionen ausbürgern würden, ähnlich wie dies über einen so langen Zeitraum mit jener jüdischen Kultur versucht wurde, ohne deren reichen Erfahrungs- und Wissensschatz es doch niemals zur Ausbildung und Ausprägung jener Zivilisation gekommen wäre, die wir gerne exklusivistisch als Abendland, als Okzident oder als den Westen bezeichnen. Die kulturhistorische Analyse von Denis de Rougemont ist klar und deutlich:

Im zwölften Jahrhundert werden wir im Languedoc und im Limousin Zeugen eines in der Geschichte einmaligen Zusammenfließens geistiger Strömungen. Auf der einen Seite eine große religiöse manichäische Strömung, die im Iran ihren Ursprung hat und die durch Kleinasien und über den Balkan bis nach Italien und Frankreich dringt mit ihrer esoteri- 
schen Lehre von der Sophia Maria und der Liebe für die „Lichtform“ des Selbst. Auf der anderen Seite eine höchst verfeinerte Rhetorik mit ihren Techniken, ihren Themen und stets wiederkehrenden Personen, mit ihren Doppeldeutigkeiten, die stets an den gleichen Stellen auftauchen, und schließlich mit ihrer Symbolik, die aus dem Irak von den platonisierenden und manichäisierenden Sufis bis ins arabische Spanien vordringt, über die Pyrenäen wandert und in Südfrankreich auf eine Gesellschaft trifft, die nur auf die sprachlichen Ausdrucksmittel zu warten schien, um auszudrücken, was sie weder in der Sprache der Geistlichkeit, noch in der volkstümlichen Sprache einzugestehen wagte, noch eingestehen konnte. Aus diesem Zusammentreffen ist die höfische Dichtung geboren worden.

So entstand am Zusammenfluss der „Häresien“ der Seele und des Begehrens, die aus demselben Orient an den beiden Ufern des Meeres der Zivilisationen entlanggewandert sind, das große westliche Modell der Sprache der leidenschaftlichen Liebe. ${ }^{12}$

Dieser discours amoureux, mit dessen Fragmenten wir uns im Verlauf dieser Vorlesung beschäftigen, ist folglich ein Produkt der transkulturellen Migration von Vorstellungen, die zumindest Anteile der altindischen, der arabischen und der christlichen Tradition miteinander vereinigen, wobei diese drei Traditionsstränge jeweils in bestimmten Häresien erscheinen, so etwa konkret in der Form arabischer Mystiker und christlicher Ketzer, von Sufis und Sekten also, für welche die Liebe eine ganz bestimmte zentrale Rolle spielte. Die höfische Liebe ist damit ein kulturelles Hybrid, das seinerseits wiederum die weitere Entwicklung der Liebeskonzeptionen im Abendland entscheidend vorantrieb.

So wäre eine Santa Teresa de Jesús, in deren Denken - im Übrigen nicht zuletzt auch auf Grund ihrer eigenen Herkunft - jüdische Elemente Eingang fanden, ohne die grundlegende orientalische Dimension gar nicht verständlich und verstehbar. Die Sprache ihrer Gottesliebe ist eine Sprache des körperlichen Begehrens, einer Sehnsucht nach der Vereinigung mit dem Geliebten in jener unio mystica, in der alles in göttlich-menschlicher Ekstase zur Einheit zusammenfließt. Bedeutet mystein das Schließen der Augen des Körpers, so sind damit bei Santa Teresa freilich nicht die Augen der Seele gemeint. Im letzten Gemach wartet der Geliebte, nachdem alle Prüfungen überstanden sind.

Die Sprache von Santa Teresa oder von San Juan de la Cruz, dem heiligen Johannes vom Kreuz, ist deswegen eine körperliche Sprache, weil die Gottesliebe gleichsam mehrfach religiös kodiert ist als geschlechtliche Liebe, die stets auch Erkenntnis im und durch den anderen ist. Daher die Hochzeitsmetaphorik, die oft erstaunlich direkte Rede von der Vereinigung, von der Verschmelzung, von der Zusammenkunft mit dem Geliebten und der verzehrenden Sehnsucht nach dem Einen, in dem man die Lichtgestalt zu finden hofft, durch die überhaupt erst die Erkenntnis zugänglich werden kann. Es ist eine göttliche und erotische

12 De Rougemont, Denis: L'amour et l'Occident, S. $117 \mathrm{f}$. 
Erkenntnis zugleich, die in der Liebe ihren Ausdruck und buchstäblich ihren Höhepunkt findet.

Wir beginnen damit zu begreifen, warum Liebe stets mehr als Liebe ist. Denn wir verstehen, warum der Diskurs der Liebe stets mehr als ein Diskurs über Liebe ist, und warum die Liebeskonzeption letztlich eine Lebenskonzeption in ganz entscheidender Weise prägt: bei den Katharern ebenso wie in der Kommune 1, bei den Festen aus Anlass des Christopher Street Day ebenso wie in der Liebeskonzeption der christlichen Mystik. Liebe besitzt eine gesellschaftspolitische Sprengkraft - eigentlich auf den ersten Blick erstaunlich, dachten wir doch, dass es sich bei der Liebe um ein höchst individuelles und zugleich intimes Gefühl handelt, das sich gerade vor der Gesellschaft und vor der Gemeinschaft abschottet.

Doch die Liebe entwirft ihr eigenes Bild von sich selbst und von der Gesellschaft - bis hin zu jener Konzeption des Lebens, in der das Leben selbst nicht das höchste Gut ist, sondern aufgegeben werden kann im Sinne jener Lust, die das letzte Wort in Richard Wagners Tristan und Isolde bildet. Der Diskurs der Liebe als Erkenntnisdiskurs durchdringt unsere Kultur noch bis hinein in die Rede von der Lust, die - folgen wir der Einsicht Friedrich Nietzsches - immer auf Ewigkeit hin angelegt ist und immer auf Ewigkeit abzielt.

Damit aber sind zugleich einige der zentralen Dimensionen von Liebe ausgemessen, die ich Ihnen im ersten, einführenden Hauptstück dieser Vorlesung vorführen wollte. Auch die Liebe in Zeiten der Moderne partizipiert noch an diesen Traditionen und Dimensionen. Und auch in ihrer desakralisiertesten Form lässt sich in der Liebe doch stets jenes Begehren erkennen oder wiedereinführen, das die Liebe im Abendland in verschiedenartigster Weise, aber letztlich doch immer konstant mit Hilfe der unterschiedlichsten symbolischen Formen kodierte.

Darum also ist Liebe stets auch Lebenswissen: Ein Wissen über die Liebe ist nicht nur ein handwerkliches, technisches Wissen, wie man Liebe macht oder mit Hilfe welcher Elemente über Liebe zu sprechen oder Liebe zu analysieren ist. Stets gibt es eine transzendente Dimension, die nach der Erkenntnis von Leben insgesamt fragt und strebt. So verstehen wir jetzt auch besser, warum in Alexander von Humboldts Die Lebenskraft oder Der rhodische Genius noch immer die Kraft der Liebe vorhanden sein muss, um die Kraft des Lebens zu beleuchten und sei es in einer griechisch-antiken Verkleidung christlicher Vorstellungen, in denen das Zusammenfallen der nackten Leiber gerade nicht mehr auf der Seite des Lebens, sondern auf jener des Todes steht. Diese thanatische Dimension des Erotischen wird uns quer durch die unterschiedlichsten Texte und Literaturen begleiten. 
